\title{
A newborn with congenital mixed phenotype acute leukemia with complex translocation t(10;11)(p12;q23) with KMT2A/MLLT10 rearranged - a report of an extremely rare case
}

\author{
DAWID SZPECHT ${ }^{I^{*}}$, JOLANTA SKALSKA-SADOWSKA ${ }^{2 *}$, BARBARA MICHNIEWICZ ${ }^{1}$, \\ JANUSZ GADZINOWSKI ${ }^{1}$, LUDMIŁA MACHOWSKA ${ }^{l}$, ANNA PIECZONKA', \\ ANNA PRZYBYŁOWICZ-CHALECKA ${ }^{3}$, ZUZANNA KANDUŁA ${ }^{3}$, \\ MAEGORZATA JARMUŻ-SZYMCZAK ${ }^{3,4}$, KRZYSZTOF LEWANDOWSKI \\ JACEK WACHOWIAK ${ }^{2}$ \\ ${ }^{1}$ Chair and Department of Neonatology, Poznan University of Medical Sciences, Poznan, Poland \\ ${ }^{2}$ Department of Pediatric Oncology, Hematology and Transplantology, Poznan University of Medical Sciences, Poznan, Poland \\ ${ }^{3}$ Department of Hematology and Bone Marrow Transplantation, Poznan University of Medical Sciences, Poznan, Poland \\ ${ }^{4}$ Institute of Human Genetics, Polish Academy of Sciences, Poznan, Poland \\ ${ }^{*}$ These authors contributed equally to this work.
}

\begin{abstract}
Neonatal congenital leukemia $(C L)$ constitutes less than $1 \%$ of all childhood leukemia cases and is diagnosed in 1 to 5 per million live births. In the neonatal period acute myeloid leukemia $(A M L)$ is described in 56-64\% of cases, acute lymphoblastic leukemia (ALL) in 21-38\% of cases and mixed-phenotype acute leukemia (MPAL) in less than $5 \%$ of cases. Rearrangements of the mixed-lineage leukemia (KMT2A alias MLL) gene are found in $>70 \%$ of infant leukemia cases. The incidence of the most frequent KMT2A rearrangements in newborns with congenital MPAL is unknown. We report a male term newborn with "blueberry muffin" syndrome, which had been noted at birth, as a presenting sign of acute leukemia. Eight-color multiparameter flow cytometry showed a blast population corresponding to a myeloid lineage with monocytic differentiation positive for CD33+/CD15+/CD11c+/CD64+/ HLA-DR+/CD4+, negative for MPO-/CD34-/CD19-/CD79a-/CD117-/CD13-/CD14-/CD36-/cCD3-/ CD2-/CD7-, and additionally positive for sCD3 (40\%). Mixed-phenotype acute leukemia according to the World Health Organization (WHO) classification was diagnosed with complex translocation t(10;11)(p12;q23) with KMT2A/MLLT10 rearrangement. The patient had an unfavorable response to chemotherapy and died on the $5^{\text {th }}$ day of life.
\end{abstract}

Key words: newborn, congenital leukemia, mixed phenotype acute leukemia.

(Centr Eur J Immunol 2018; 43 (3): 346-352)

\section{Introduction}

Neonatal congenital leukemia (CL) constitutes less than $1 \%$ of all childhood leukemia cases and is diagnosed in 1 to 5 per million live births. In the neonatal period (up to 28 days after birth) acute myeloid leukemia (AML) is described in $56-64 \%$ of cases, acute lymphoblastic leukemia (ALL) in $21-38 \%$ of cases and mixed-phenotype acute leukemia (MPAL) in less than 5\% of cases [1]. Several factors may be associated with the development of leukemia in a newborn: maternal exposure to radiation, high birth weight, high level of insulin-like growth factors, exposure to marijuana, and topoisomerase-II inhibitors such as coffee, tea, cocoa, wine, and soy products [2,3]. Diagnosis of perinatal leukemia should be based on three major criteria: presence of immature hematopoietic cells in the peripheral blood and bone marrow, hematopoietic cell infiltration into non-hematopoietic tissue, and exclusion of other conditions by differential diagnosis [1]. In 25-30\% of all cases infiltration of subcutaneous tissues by leukemic cells is found. Skin symptoms are called "blueberry-muffin" syndrome and should be differentiated from TORCH (toxoplasmosis, rubella, cytomegalovirus, herpes simplex virus), blue rubber bleb nevus syndrome, Langerhans cell histiocytosis, cutaneous mastocytosis and other hematological disorders [3]. The prog-

Correspondence: Dawid Szpecht, MD, Asst. Prof., Chair and Department of Neonatology, Poznan University of Medical Sciences, 33 Polna St., 60-535 Poznan, Poland, e-mail: dawid.szpecht@poczta.fm Submitted: 3.07.2018; Accepted: 21.08.2018 
nosis of CL remains poor, although spontaneous remissions are observed [4].

Rearrangements of the mixed-lineage leukemia (KMT2A alias $M L L)$ gene are found in $>70 \%$ of infant leukemia cases and generally confer a poor prognosis. There are more than 120 known fusion partners of KMT2A having some correlation with disease phenotype and prognosis. AF4/KM$T 2 A$ fusion, a result of a $\mathrm{t}(4,11)(\mathrm{q} 21, \mathrm{q} 23)$ translocation, is responsible for approximately $50 \%$ of cases of infant acute leukemias. ALL1-fused from chromosome 9 (AF9) and eleven-nineteen leukemia $(E N L)$ are the second and third most common fusion partners of $K M T 2 A$, and these fusions arise from the $\mathrm{t}(9,11)(\mathrm{p} 22, \mathrm{q} 23)$ and $\mathrm{t}(11,19)(\mathrm{q} 23, \mathrm{p} 13.3)$ translocations [5]. The incidence of the most frequent KMT2A rearrangements in newborns with congenital MPAL is unknown. The first neonatal case report of congenital MPAL in the literature was described in 2015. However, in this case cytogenetic analysis showed a normal female karyotype, and FISH results for translocations or deletions involving the KMT2A gene and for monosomy 7 or $7 \mathrm{q}$ deletions were negative [6].

\section{Case report}

\section{Clinical course}

We report a case of a male infant born in the Clinical Hospital of Gynecology and Obstetrics at the Poznan Uni- versity of Medical Sciences at 40 weeks of gestation to a 38-year-old gravida 1 mother, whose pregnancy had been uncomplicated. The detailed history for maternal exposure to mutagenic agents or an underlying genetic predisposition for malignancy was negative. The infant was delivered via caesarean section for fetal decelerations following the spontaneous onset of labor. Apgar scores were 4 and 8 at 1 and 5 minutes of life, respectively. After the birth in the 3rd minute of life the neonate was intubated due to respiratory insufficiency and was admitted to the Neonatal Intensive Care Unit, Department of Neonatology, Poznan University of Medical Sciences. Initial examination of the skin confirmed diffuse, multiple dome-shaped, bluish-red violaceous, non-tender papules and nodules (blueberry muffin appearance) and multiple petechiae (Fig. 1). There was decreased spontaneous movement associated with decreased muscle tone of upper and lower extremities.

On the 2nd day of life the patient was extubated, and on non-invasive ventilation support transported to the Department of Pediatric Oncology, Hematology and Transplantology (DPOHT), Poznan University of Medical Science. On admission, the clinical condition of the neonate was severe, with respiratory distress, poor activity, multiple skin hemorrhages, and generalized neonatal scleroderma. Laboratory findings indicated hypoxemia, lactic acidosis and coagulopathy. Cranial ultrasound showed increased periventricular echogenicity. In abdominal
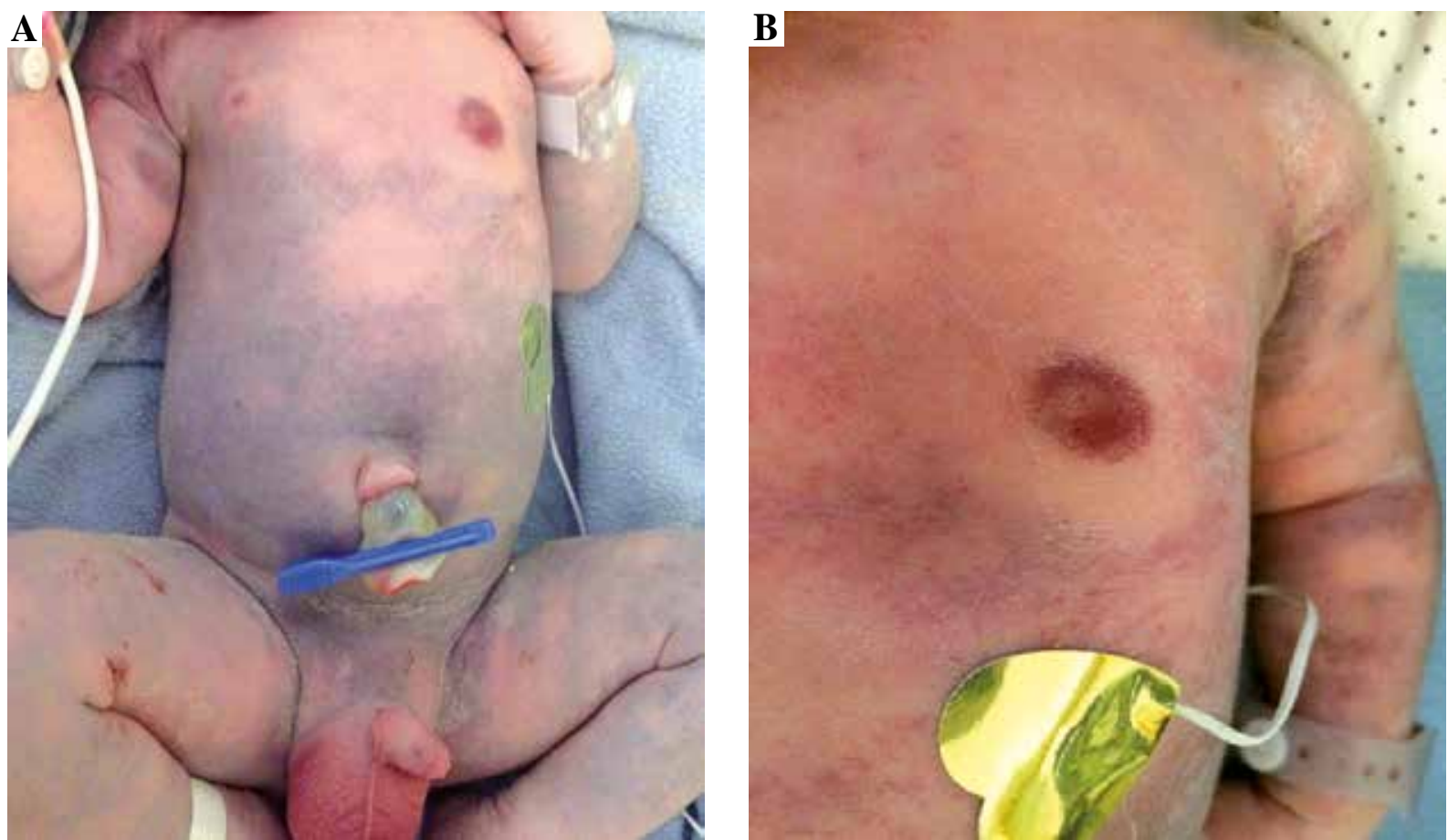

Fig. 1. Multiple dome-shaped, bluish-red violaceous, non-tender papules and nodules (blueberry muffin appearance) and multiple petechiae 
ultrasound hepatosplenomegaly was found. Pleural and testicular ultrasound results were normal.

\section{Laboratory, flow cytometry and genetic findings}

Initial laboratory studies done in the first hours of life showed hyperleucocytosis (91.6 G/1, normal range: 8-30 $\mathrm{G} / \mathrm{l}$ ), anemia (hemoglobin level - $7.1 \mathrm{mmol} / 1$, normal range: $8.3-12.4 \mathrm{mmol} / \mathrm{l}$; hematocrit $-0.317 \mathrm{l} / \mathrm{l}$, normal range $0.396-0.573 \mathrm{l} / \mathrm{l})$ and thrombocytopenia $(20 \mathrm{G} / \mathrm{l}$, normal range: $114-449 \mathrm{G} / 1$ ). Laboratory findings specific for tumor lysis syndrome, including elevated uric acid level (9.3 mg/dl, normal range: $3-5 \mathrm{mg} / \mathrm{dl})$, were found.

Bone marrow aspiration performed on the 1st day of life showed infiltration by leukemic cells (48\%), predominantly promonocytes. Eight-color multiparameter flow cytometry showed a blast population corresponding to a myeloid lineage with monocytic differentiation positive for $\mathrm{CD} 33+$ / CD15+/CD11c+/CD64+/HLA-DR+/CD4+, negative for MPO-/CD34-/CD19-/CD79a-/CD117-/CD13-/CD14-/ CD36-/cCD3-/CD2-/CD7-, and additionally positive for
sCD3 (40\%). Mixed-phenotype acute leukemia (MPAL) according to the WHO classification was diagnosed [7].

Chromosomal analysis of a peripheral blood sample was performed on 23 metaphases, two of which showed a normal karyotype. Translocation involving the $\mathrm{p}$ and $\mathrm{q}$ arm of chromosome 10 and the $q$ arm of chromosome 11 was detected in 21 metaphases $(86 \%)$. The translocation was found as the sole abnormality in 6 metaphases and with additional monosomies in the remaining 10 hypodiploid and 5 hyperhaploid ones. Interphase FISH study confirmed 11q23 rearrangement (KMT2A gene locus) in $80 \%$ of interphase nuclei examined. Metaphase FISH with a KMT2A probe showed a 3'KMT2A signal (red) on the short arm of derivative chromosome $10(\operatorname{der}(10))$ and 5'KMT2A on derivative 11 (Fig. 2C), a WCP10 probe was present on $\operatorname{der}(10)$ and on derivative $11(\operatorname{der}(11))$ (Fig. 2D), and additionally a 10qtel probe (D10S2290) was present on the $\mathrm{q}$ arm of the normal chromosome 10 and the long arm of der(10) (Fig. 2). The karyotype was defined as:
A

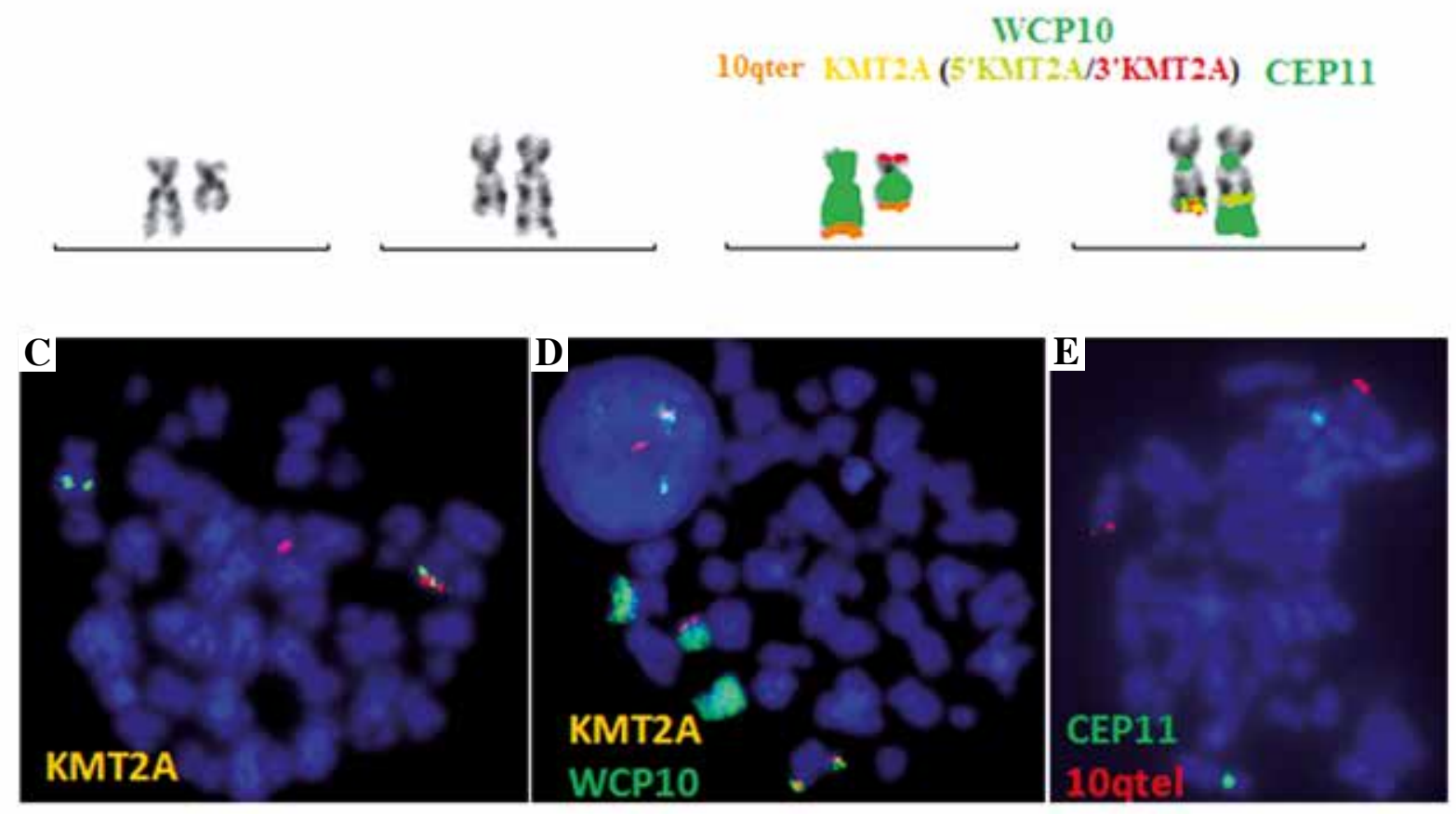

Fig. 2. A) G-banding patterns of chromosomes 10 and 11 ; B) G-banding patterns of chromosomes 10 and 11 with graphic interpretation of rearrangements involving 10p, 10q and 11q; C) Fluorescence in situ hybridization (FISH) using MLL break-apart probe on a metaphase showed a KMT2A rearrangement - split signal (red and green) and the normal colocalized red-green signal; D) FISH using MLL break-apart probe and whole chromosome painting probe for chromosome 10 (WCP10) reveals translocation of 10q to 11q; E) FISH using 10q telomere probe (D10S2290) and 11 centromere probe (CEP11) reveals 10qtel probe signals on normal 10 and der(10) chromosomes 
46,XY, der $(10)(?:: \mathrm{p} 12 \rightarrow \mathrm{q} ?:: \mathrm{q} ?), \mathrm{der}(11)$ $(11 \mathrm{pter} \rightarrow 11 \mathrm{q} 23:: 10 \mathrm{q} ? 24 \rightarrow 10 \mathrm{q} ?)[6] / 43 \sim 45, \mathrm{XY},-$ 1 [2],-6[2], der(10)(?::p12 $\rightarrow$ q?::q?)[10], $\operatorname{der}(11)$ $(11 \mathrm{pter} \rightarrow 11 \mathrm{q} 23:: 10 \mathrm{q} ? 24 \rightarrow 10 \mathrm{q}$ ?)[10],-16[2],-19[3],$21[5][\mathrm{cp} 10] / 32 \sim 34, \mathrm{X},-\mathrm{Y}[2],-1[2],-2[2],-3[2],-5[3],-$ 6[2],-7[3],der(10)(?::p12 $\rightarrow$ q?11.2::?)[4], $\operatorname{der}(11)$ $(11$ pter $\rightarrow 11 q 23:: 10 q ? 24 \rightarrow 10 q$ ?)[4],-11[4],-15[5],-16[2],17[4],-18[4],-18[3],-19[4],-20[3],-21[5],-22[5][cp5];

ish $\operatorname{der}(10)(?:: 10 \mathrm{p} 12 \rightarrow 10 \mathrm{q}$ ?)(3'MLL+, wcp $10+$, D10S2290+), der(11)(11pter $\rightarrow 11 \mathrm{q} 23:: 10 \mathrm{q} ? 24 \rightarrow 10 \mathrm{q}$ ?) (D11Z1+,5'MLL+,3'MLL-,wcp10+)/46,XY[2].

To confirm the cytogenetic findings and identify the KMT2A gene partner multiplex RT-PCR was performed. Total RNA was isolated from mononuclear cells from a peripheral blood sample using TRIzol reagent, then reverse transcribed with the SuperScript VILO cDNA Synthesis Kit. Multiplex RT-PCR was performed according to the protocol proposed by Burmeister et al. [8]. Amplified products were analyzed using a QIAxcel DNA high resolution cartridge. The results indicated MLLT1O as a KMT2A partner gene. The observed amplicon contained a $\mathrm{t}(10 ; 11)$ (p12;q23) translocation.

\section{Treatment and outcome}

Treatment included hydration, erythrocyte and thrombocyte transfusions, correction of acidosis and coagulation imbalances, empirical antibiotics and antimycotics. The patient received rasburicase and chemotherapy with lowdose Ara-C ( $0.5 \mathrm{mg} / \mathrm{kg} /$ day) on the basis of predominantly monocytic differentiation of the leukemic clone. Due to respiratory deterioration and progressive pulmonary hypertension re-intubation was necessary 4 hours later and the patient was referred to an intensive care unit for mechanical ventilation with nitrogen monoxide inhalation. After transient improvement with normalization of blood gas results, WBC dropped to $8 \times 10^{9} / 1$ and lactate decreased from 12 to $8 \mathrm{mmol} / \mathrm{l}$, and on the 3 rd day the neonate became hypotensive. The Ara-C dose was increased to $1.0 \mathrm{mg} / \mathrm{kg} /$ day and continued until the 4th day of life. Despite continuous infusion of dobutamine, massive circulatory deterioration with recurrence of pulmonary hypertension and WBC increase to $76 \times 10^{9} / 1$ occurred. On the 5 th day of life, due to therapy resistance, persisting leucocytosis and progressive respiratory and circulatory insufficiency, the hospital ethics committee determined that it was permissible to withdraw oncological treatment. The neonate died a few hours later.

\section{Discussion}

Clinical presentation of our patient shares all the most common symptoms of CL [9-13]. Rearrangement of the KMT2A gene at chromosome $11 \mathrm{q} 23$ as the primary clonal genetic defect in the present case along with immunopheno- type with dominant monocytic characteristics expressed by CD11c+/CD15+/CD33+/CD64+ also falls into a set of the most common features of CL [7]. However, co-expression of T-ALL-associated antigen CD3 suggested origin in a stem cell not fully committed to myeloid differentiation [7].

Translocation $\mathrm{t}(10 ; 11)(\mathrm{p} 12 ; \mathrm{q} 23)$ identified in the patient accounts for approximately $10 \%$ of all KMT2A-rearranged AML cases and is the second most common translocation in pediatric KMT2A-rearranged AML [14]. It is mostly associated with subtype FAB M5, rarely reported in other AML subtypes, therapy-related AML, MPAL, and B-cell acute lymphoblastic leukemia (B-ALL). Association of this aberration with T-cell acute lymphoblastic leukemia (T-ALL) is reported extremely rarely $[2,15]$. This recurrent rearrangement involves the KMT2A gene (alias $M L L$ ) on chromosome 11 band q23 with the MLLT1O (previously called $A F 10$ ) gene at $10 \mathrm{p} 12$ to produce the KMT2A/ $M L L T 10$ fusion transcript $[2,16]$. Unlike in translocations involving the majority of over 120 known KMT2A partners [17], KMT2A and MLLT10 are in opposite transcriptional directions, which means that complex rearrangements with three or more breaks are often required to yield the functional fusion. Thus, combined cytogenetic, molecular and FISH analyses are necessary for an accurate diagnosis [18-20]. In the studied case the aberration affected not only the 10p12 locus but also a locus on the long arm of chromosome 10 , while more precise clarification was unavailable. This translocation should be distinguished from other rare rearrangements known in infant leukemia fusing the $K M T 2 A$ gene with genes localized in the close vicinity to $M L L T 10: N E B L$ or $A B I 1[18,21]$. In a study of 756 children with $K M T 2 A$-rearranged AML, translocation $\mathrm{t}(10 ; 11)(\mathrm{p} 12 ; \mathrm{q} 23)$ was established as an independent predictor of unfavorable prognosis with 5-year event-free survival (EFS) and overall survival (OS) of $32 \%$ each and probability of cumulative incidence of relapse of $52 \%$ [14]. However, the prognostic significance of this genetic entity may not be fully recognized due to molecular heterogeneity of the translocation and the small number of documented cases, including very sparse data on leukemia of neonates, which are presented in Table 1 [2, 22-24].

Leukemia with a blast population expressing antigens of more than one lineage is defined as MPAL and accounts for $<5 \%$ of pediatric leukemia cases [25]. MPAL $K M T 2 A$ - (alias $M L L-$ ) rearranged is a separate entity according to the World Health Organization (WHO) classification with the incidence estimated at $12-18 \%$ of all MPAL cases in children [26]. There is strong molecular evidence that KMT2A abnormalities occur in utero and both $K M T 2 A$ rearranged leukemia and MPAL may originate very early during hematopoietic differentiation from stem cells with bipolar lymphoid and myeloid differentiation potential [27]. Diagnosis of MPAL is based on a scoring system first published by European Group for Immunological Characterization of Acute Leukemias 
Table 1. Summary of the clinicopathologic findings of three neonatal cases of KMT2A/MLLT10-positive leukemia reported in literature

\begin{tabular}{|c|c|c|c|c|c|c|}
\hline Ref. & Age & Type of leukemia & Details of rearrangement & Diagnostic tools & Therapy & Outcome \\
\hline [22] & $\begin{array}{c}0.04 \\
\mathrm{yr}\end{array}$ & $\begin{array}{c}\text { AML } \\
\text { FAB M5 }\end{array}$ & Insertion of $11 \mathrm{q} 23$ into $10 \mathrm{p}$ & FISH & $\begin{array}{c}\text { AML MM- } \\
2000 \text { protocol } \\
\text { and auto-HSCT }\end{array}$ & EFS and OS $10.3 \mathrm{mo}$ \\
\hline [23] & ng & preB-ALL & $\begin{array}{c}\text { Interstitial insertion of MLLT10 } \\
\text { gene into } 11 \mathrm{q} 23\end{array}$ & $\begin{array}{c}\text { Karyotyping } \\
\text { FISH } \\
\text { RT-PCR } \\
\end{array}$ & $\begin{array}{l}\text { AIEOP ALL } \\
9502 \text { protocol }\end{array}$ & $\begin{array}{l}\text { EFS and OS } 24 \text { mo, } \\
\text { severe cardiotoxicity }\end{array}$ \\
\hline \multirow[t]{2}{*}{ [24] } & \multirow[t]{2}{*}{$\begin{array}{c}10 \\
\text { days }\end{array}$} & \multirow{2}{*}{$\begin{array}{c}\text { Intestinal } \\
\text { myeloid sarcoma } \\
\text { consistent with an } \\
\text { undifferentiated } \\
\text { leukemia with } \\
\text { partial monoblastic } \\
\text { differentiation }\end{array}$} & $\begin{array}{l}\text { KMT2 rearrangement in } \\
\text { intestinal infiltration }\end{array}$ & FISH & \multirow[t]{2}{*}{$\begin{array}{l}\text { Spontaneous } \\
\text { remission } \\
\text { of neonatal } \\
\text { symptoms }\end{array}$} & \multirow{2}{*}{$\begin{array}{l}\text { at } 5 \text { months age full blown } \\
\text { AML FAB M5 KMT2A/ } \\
M L L T 10 \text {-positive treated } \\
\text { with allo-HSCT post AML } \\
\text { BFM } 2012 \text { protocol; } \\
\text { EFS and OS } 9 \text { mo }\end{array}$} \\
\hline & & & $\begin{array}{l}K M T 2 A / M L L T 10 \text { fusion } \\
\text { transcript positive in bone } \\
\text { marrow, while FISH negative } \\
\text { for } K M T 2 A \text { rearrangement }\end{array}$ & RT-PCR & & \\
\hline
\end{tabular}

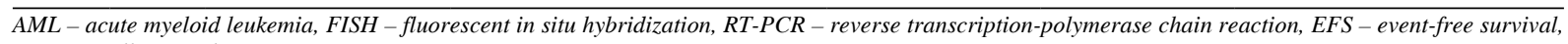
OS - overall survival

Table 2. Summary of clinicopathologic findings of two neonatal mixed-phenotype acute leukemia (MPAL) cases reported in literature

\begin{tabular}{|c|c|c|}
\hline & Ref. [25] & Ref. [6] \\
\hline Type of publication & Study of 35 childhood MPAL cases in children & Case report \\
\hline Age & 2 days & 10 days \\
\hline $\begin{array}{l}\text { History and clinical } \\
\text { presentation }\end{array}$ & Not given & $\begin{array}{l}\text { Twin, product of in vitro fertilization pregnancy, dermal } \\
\text { nodules, peripheral facial nerve palsy }\end{array}$ \\
\hline Immunophenotype & $\begin{array}{c}\text { CD19, CD22, CD24, } \\
\text { cyCD79a } \\
\text { CD56 TdT CD11b, CD13, CD14, CD33, CD36, } \\
\text { CD64, CD6 }\end{array}$ & $\begin{array}{c}\text { Bone marrow: (CD45) 85.4\%, CD3 62.8\%, CD5 63.7\%, CD7 } \\
\text { 68.3\%, and CD10, CD13, CD15, CD19, CD20, CD22, CD33, } \\
\text { CD34, CD79a, CD117, Tdt, and HLA-DR negative; } \\
\text { Skin biopsy: MPO positive and TdT/CD117/S-100 and CD1a } \\
\text { negative }\end{array}$ \\
\hline Type of MPAL & Bilineal B-lymphoid/myeloid & Bilineal T-lymphoid/myeloid \\
\hline Cytogenetics & 46,XY,t(9;11)(p13;q23)18/46,XY2 & $\begin{array}{l}\text { 46,XX; FISH for } 11 \mathrm{q} 23 \text { and chromosome } 7 \text { aberrations } \\
\text { negative }\end{array}$ \\
\hline Initial therapy & Standard protocol for AML & Interfant-99 protocol \\
\hline Response & Non-responder & Not achieved \\
\hline $\begin{array}{l}\text { Additional therapy and } \\
\text { outcome }\end{array}$ & $\begin{array}{c}\text { Protocol for ALL } \rightarrow \text { CR (MRD+) HSCT } \rightarrow \text { toxic } \\
\text { death, OS } 0.4 \mathrm{yr}\end{array}$ & Toxic death at $15^{\text {th }}$ day of therapy \\
\hline
\end{tabular}

(EGIL) and modified in 2008 to the WHO classification currently in force. Although according to the majority of publications cytoplasmic CD3 expression in a leukemic clone is a necessary marker of T-lineage involvement for MPAL diagnosis [25-27], according to the WHO, positivity of surface CD3 antigen is also its alternative approved indicator [15]. Therefore our case, diagnosed on the first day of life, is considered as a rare example of the T-lymphoid/myeloid subtype of MPAL $\mathrm{t}(\mathrm{v} ; 11 \mathrm{q} 23)$; $K M T 2 A$ rearranged $[15,26]$ and supplements the first description by Lou et al. of MPAL t(10;11)(p12;q23); KMT2A/MLLT10-positive in a 6-month-old infant [28]. Data on neonatal MPAL are almost non-existent. The data on the two cases are presented in Table 2. The prognosis in our case was difficult to predict; nevertheless, unfavorable factors were cumulated: leukemia at birth, mixed phenotype, high-risk genetic profile and generally severe clinical condition. No prospective, controlled trials exist to guide therapy either in CL or MPAL [29]. In MPAL it is usually started with AML-directed therapy or ALL-directed ther- 
apy and switches if the initial treatment fails [27], though recently limited data have emerged suggesting that higher remission rates are achieved with acute lymphoblastic leukemia-like induction regimens. Allogenic bone marrow transplantation in first remission may be associated with improved survival compared with consolidation chemotherapy [29].

In conclusion, we have presented a case of a 1-dayold neonate with MPAL showing co-expression of myeloid and T-lymphoid markers and carrying complex translocation $\mathrm{t}(10 ; 11)(\mathrm{p} 12 ; \mathrm{q} 23)$ with $K M T 2 A / M L L T 10$ rearrangement. It underscores that $\mathrm{CL}$ has to be included in differential diagnosis of neonates, requires in-depth immunophenotypic, molecular, genetic studies and remains a therapeutic challenge.

\section{Acknowledgements}

All procedures performed in the study were in accordance with the ethical standards of the institutional and/or national research committee and with the 1964 Helsinki declaration and its later amendments or comparable ethical standards.

Informed consent was obtained from parents of the patient.

The authors wish to thank Benigna Konatkowska for being an important contributor to the therapy of the patient.

The authors declare no conflict of interest.

\section{References}

1. van der Linden MH, Creemers S, Pieters R (2017): Diagnosis and management of neonatal leukaemia. Semin Fetal Neonatal Med 17: 192-195. doi: 10.1016/j.siny.2012.03.003

2. Lillington DM, Young BD, Berger R, et al. (1998): The $\mathrm{t}(10 ; 11)(\mathrm{p} 12 ; \mathrm{q} 23)$ translocation in acute leukaemia: a cytogenetic and clinical study of 20 patients. European 11q23 Workshop participants. Leukemia 12: 801-804.

3. Pansy J, Morris N, Resch B (2015): Extensive blueberry muffin rash in a neonate. Arch Dis Child Fetal Neonatal Ed 100: F115.

4. Dinulos JG, Hawkins DS, Clark BS, Francis JS (1997): Spontaneous remission of congenital leukemia. J Pediatr 131: 300303. doi: 10.1016/S0022-3476(97)70170-7

5. Meyer C, Hofmann J, Burmeister T, et al. (2013): The MLL recombinome of acute leukemias in 2013. Leukemia 27: 2165-2176. doi: 10.1038/leu.2013.135

6. Ergin H, Özdemir ÖM, Karaca A, et al. (2015): A newborn with congenital mixed phenotype acute leukemia after in vitro fertilization. Pediatr Neonatol 56: 271-274. doi: 10.1016/j. pedneo.2013.03.016

7. Dworzak MN, Buldini B, Gaipa G, et al. (2018): AIEOPBFM consensus guidelines 2016 for flow cytometric immunophenotyping of pediatric acute lymphoblastic leukemia. Cytometry B Clin Cytom 94: 82-93. doi: 10.1002/cyto.b.21518
8. Burmeister T, Meyer C, Gröger D, et al. (2017): Evidence-based RT-PCR methods for the detection of the 8 most common MLL aberrations in acute leukemias. Leuk Res 39: 242-247. doi: 10.1016/j.leukres.2014.11.017

9. Bresters D, Reus AC, Veerman AJP, et al. (2002): Congenital leukaemia: The Dutch experience and review of the literature. Br J Haematol 117: 513-524. doi: 10.1046/j.13652141.2002.03459.x

10. Bayhan T, Çiki K, Tavil B, et al. (2015): An infant with congenital leukemia cutis and AML-M5 with MLL gene rearrangement. J Pediatr Hematol Oncol 37: 566-567.

11. Picone S, Aufieri R, Bressan K, Paolillo P (2014): Leukemia cutis in an infant with congenital leukemia and tetralogy of fallot. J Clin Neonatol 3: 122-123. doi: 10.4103/22494847.134715

12. Lee EG, Kim TH, Yoon MS, Lee HJ (2013): Congenital leukemia cutis preceding acute myeloid leukemia with $\mathrm{t}(9 ; 11)$ (p22;q23), MLL-MLLT3. J Dermatol 40: 570-571. doi: $10.1111 / 1346-8138.12164$

13. Isaacs H (2003): Fetal and neonatal leukemia. J Pediatr Hematol Oncol 25: 348-361. doi: 10.1097/00043426-20030500000002

14. Balgobind BV, Raimondi SC, Harbott J, et al. (2009): Novel prognostic subgroups in childhood 11q23/\&lt;em\&gt;MLL\&lt;/ em\&gt;-rearranged acute myeloid leukemia: results of an international retrospective study. Blood 114: 2489-2496.

15. Swerdlow SH, Campo E, Harris NL, et al. (2008): WHO Classification of Tumours of Haematopoietic and Lymphoid Tissues. Lyon, France. World Health Organ Classification Tumours Haematop Lymphoid Tissue. doi: 10.1017/ CBO9781107415324.004

16. Morerio C, Rapella A, Tassano E, et al. (2005): MLL-MLLT10 fusion gene in pediatric acute megakaryoblastic leukemia. Leuk Res 29: 1223-1226. doi: 10.1016/j.leukres.2005.03.008

17. DiNardo CD, Tang G, Pemmaraju N, et al. (2015): Acute myeloid leukemia with $\mathrm{t}(10 ; 11)$ : a pathological entity with distinct clinical presentation. Clin Lymphoma Myeloma Leuk 15: $47-$ 51. doi: 10.1016/j.clml.2014.06.022

18. Klaus M, Schnittger S, Haferlach T, et al. (2003): Cytogenetics, fluorescence in situ hybridization, and reverse transcriptase polymerase chain reaction are necessary to clarify the various mechanisms leading to an MLL-AF10 fusion in acute myelocytic leukemia with 10;11 rearrangement. Cancer Genet Cytogenet 144: 36-43. doi: 10.1016/S0165-4608(02)00876-2

19. Gore L, Ess J, Bitter MA, et al. (2000): Protean clinical manifestations in children with leukemias containing MLL-AF10 fusion. Leukemia 14: 2070-2075. doi: 10.1038/sj.leu.2401966

20. Beverloo HB, Le Coniat M, Wijsman J, et al. (1995): Breakpoint heterogeneity in $\mathrm{t}(10 ; 11)$ translocation in AML-M4/M5 resulting in fusion of AF10 and MLL is resolved by fluorescent in situ hybridization analysis. Cancer Res 55: 4220-4224.

21. Morerio C, Rosanda C, Rapella A, et al. (2002): Is t(10;11) (p11.2;q23) involving MLL and ABI-1 genes associated with congenital acute monocytic leukemia? Cancer Genet Cytogenet 139: 57-59. doi: 10.1016/S0165-4608(02)00616-7

22. Stasevich I, Utskevich R, Kustanovich A, et al. (2006): Translocation $(10 ; 11)(\mathrm{p} 12 ; \mathrm{q} 23)$ in childhood acute myeloid leukemia: incidence and complex mechanism. Cancer Genet Cytogenet 169: 114-120. doi: 10.1016/j.cancergencyto.2006.03.011

23. Angioni A, La Starza R, Mecucci C, et al. (1998): Interstitial insertion of AF10 into the ALL1 gene in a case of infant acute lymphoblastic leukemia. Cancer Genet Cytogenet 107: 107110. doi: 10.1016/S0165-4608(98)00105-8 
24. Gyárfás T, Wintgens J, Biskup W, et al. (2016): Transient spontaneous remission in congenital MLL-AF10 rearranged acute myeloid leukemia presenting with cardiorespiratory failure and meconium ileus. Mol Cell Pediatr 3: 30. doi: 10.1186/ s40348-016-0061-7

25. Rubnitz JE, Onciu M, Pounds S, et al. (2009): Acute mixed lineage leukemia in children: the experience of St Jude Children's Research Hospital. Blood 113: 5083-5089.

26. Porwit A, Béné MC (2015): Acute leukemias of ambiguous origin. Am J Clin Pathol 144: 361-376. doi: 10.1309/AJCPSTU55DRQEGTE

27. Matutes E, Pickl WF, Van't Veer M, et al. (2011): Mixed-phenotype acute leukemia: clinical and laboratory features and outcome in 100 patients defined according to the WHO 2008 classification. Blood 117: 3163-3171.

28. Lou Z, Zhang CC, Tirado CA, et al. (2010): Infantile mixed phenotype acute leukemia (bilineal and biphenotypic) with $\mathrm{t}(10 ; 11)(\mathrm{p} 12 ; \mathrm{q} 23) ;$ MLL-MLLT10. Leuk Res 34: 1107-1109. doi: 10.1016/j.leukres.2010.02.029

29. Wolach O, Stone RM (2017): Mixed-phenotype acute leukemia: current challenges in diagnosis and therapy. Curr Opin Hematol 24: 139-145. 